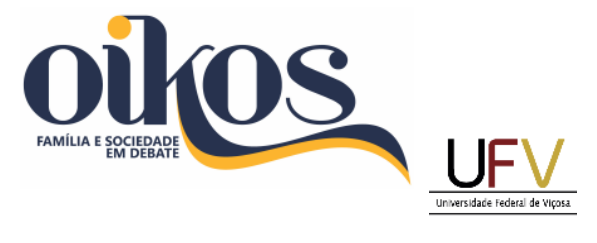

\title{
A PANDEMIA POR COVID-19 E SEUS REFLEXOS NA FAMÍLIA
}

\author{
Débora Pires Teixeira ${ }^{1}$ \\ Fabiano Eloy Atílio Batista ${ }^{2}$ \\ Rita de Cássia Pereira Farias ${ }^{3}$
}

A Covid-19 é uma doença respiratória aguda que foi identificada pela primeira vez em Wuhan, na China, em dezembro de 2019. Sua rápida expansão fez com que a Organização Mundial da Saúde (OMS) declarasse, em 30 de janeiro de 2020, que o surto da doença causada pelo novo coronavirus constituía uma Emergência de Saúde Pública de Importância Internacional - o mais alto nível de alerta da Organização, como previsto no Regulamento Sanitário Internacional.

Em 11 de março de 2020, diante da ampliação exponencial da doença pelo mundo, a OMS a caracterizou como uma pandemia (OPAS BRASIL, 20204) e, frente a essa situação, governantes de várias partes do mundo adotaram como medida protetiva a prática do isolamento social, atrelada ao funcionamento restrito de serviços tidos como essenciais. Nos locais onde a transmissão encontra-se em estágios mais avançados, gerando um elevado número de mortes, há, ainda, a opção pelo lockdown, um formato de isolamento mais radical no qual a circulação de pessoas em espaços públicos fica proibida. À medida que reduz ou amplia o número de contaminados, os governos respondem flexibilizando ou ampliando as restrições para 0 isolamento social.

No entanto, mesmo diante do processo de vacinação em curso, o ano de 2021 tem sido marcado pelo exponencial aumento do número de casos e de mortes por Covid-19 no território

\footnotetext{
${ }_{1}^{1}$ Doutora em Economia Doméstica pela Universidade Federal de Viçosa. Professora Adjunta do Instituto de Ciências Sociais e Aplicadas da Universidade Federal Rural do Rio de Janeiro. Email: deborapite@gmail.com Orcid: https://orcid.org/0000-0002-3143-8676

2 Doutorando e Mestre pelo Programa de Pós-Graduação em Economia Doméstica (PPGED) - área de concentração em Família e Sociedade - pela Universidade Federal de Viçosa (UFV). Email: fabiano.batista@ufv.br Orcid: https://orcid.org/0000-0001-7067-560X

${ }^{3}$ Doutora em Antropologia Social pela Universidade Estadual de Campinas. Professora do Curso de Graduação em Serviço Social e do Programa de Pós-Graduação em Economia Doméstica da Universidade Federal de Viçosa. Email: rcfarias@ufv.br Orcid: http://orcid.org/0000-0002-8108-5370

${ }^{4}$ ORGANIZAÇÃO PANAMERICANA DE SAÚDE/BRASIL-OPAS/BRASIL. Folha informativa - CoVID-19 (doença causada pelo novo coronavírus). https://www.paho.org/bra/index.php?option=com content\&view=article\&id=6130:covid-19-materiais-decomunicacao\&ltemid=0\#atividade. Acesso em: 13 ago. 2020.
} 
brasileiro. Até o dia nove de abril de 2021, havia 133.552.774 casos confirmados da doença no mundo e 2.894.295 de mortes, enquanto no Brasil tem-se 13.193.205 e mais de 340 mil mortes, respectivamente (WHO, 20215), colocando o País como epicentro da crise sanitária.

No geral, além do medo do contágio e das perdas iminentes, a nova realidade imposta pela pandemia estabeleceu diversos desafios na vida dos sujeitos, produzindo reflexos em seu cotidiano. As mudanças recentes nos padrões de convívio familiar afetaram as relações internas das famílias, que envolvem diferentes aspectos, como apontam os artigos que atenderam a chamada para a composição do Dossiê Família e Covid-19: entre a Proteção e a Desproteção, primeiro número do $31^{\circ}$ volume da revista OIKOS: Família e Sociedade em Debate, seção que reúne oito artigos.

$\mathrm{Na}$ análise dos textos do Dossiê, percebeu-se a recorrência a três temáticas predominantes: Família, Gênero e a Pandemia por Covid-19, Família, Geração e Pandemia por Covid-19 e Trabalho, Categorias Profissionais e a Pandemia por Covid-19, como destacado a seguir.

A temática Família, Gênero e a Pandemia por Covid-19 agrupou três artigos. O primeiro deles, uma revisão de literatura intitulada Reflexões sobre trabalho e gênero na pandemia do Covid-19, de autoria de Dayse Amâncio dos Santos e Laurileide Barbosa da Silva, analisou a relação entre trabalho e gênero no cenário atual de pandemia causada pelo Covid-19, tratando especificamente do trabalho feminino na área da saúde e no espaço doméstico (remunerado ou não), durante o processo de isolamento. De natureza documental, o artigo trouxe como resultado a permanência das disparidades de gênero no tocante do trabalho executado por mulheres, que são historicamente presentes na sociedade brasileira e foram reforçadas pelo contexto pandêmico.

Dialogando com o texto anterior, o artigo Famílias, mulheres e cuidados: efeitos da pandemia de Covid-19 em Santa Catarina - de Edilane Bertelli, Liliane Moser e Carmen Rosario Ortiz Gutierrez Gelinski, apresentou uma análise sobre os efeitos da pandemia por Covid-19 na dinâmica de famílias e no cotidiano de mulheres em decorrência do isolamento social, partindo de um estudo exploratório realizado entre os meses de maio a junho de 2020 com famílias residentes no estado de Santa Catarina, agrupando 2101 respondentes. Semelhante ao estudo de Santos e Silva, as autoras apontam para a percepção de uma sobrecarga sob as mulheres com a realização de trabalho remunerado e não remunerado na

${ }^{5}$ WORLD HEALTH ORGANIZATION - WHO. WHO Coronavirus Disease (COVID-19) Dashboard, 9 april 2021. Disponível em: https://covid19.who.int/. Acesso em: 04 marc. 2021. 
esfera privada da casa, associado ao acompanhamento dos filhos submetidos ao ensino remoto, corroborando as desigualdades de gênero nas esferas do trabalho e do cuidado.

Ainda sobre questões de gênero, no texto Feminicídio durante a pandemia da Covid19, Rosário Martinho Sunde, Lucildina Muzuri Conferso Sunde e Larissa Fenalte Esteves analisaram o índice de mulheres vítimas de feminicídio no período da pandemia da Covid-19, tendo como base o mês de junho de 2020. Como resultados, os autores apontam para um crescimento exponencial desse índice, indicando o processo de isolamento social como fator de risco para essas vítimas.

No que tange a temática Família, Geração e Pandemia por Covid-19 foram apresentados três textos envolvendo faixas etárias que incluem desde as crianças até os idosos e apresentam suas inter-relações familiares no contexto pandêmico. No primeiro deles, Direito de família em tempos de pandemia, Vanessa dos Santos Moura, valendo-se de uma revisão sistemática, buscou responder a problemática que envolve o exercício da guarda compartilhada entre os casais parentais em tempos de isolamento social, com restrição de circulação de pessoas. No decorrer do texto a autora problematiza os direitos individuais dos pais e o bem coletivo, com a redução do contágio. Dentre os apontamentos, a autora sugere a adoção de sociabilidades digitais para mitigar as perdas de garantias individuais.

Gustavo Bruno Pereira de Souza, Maria das Dores Saraiva de Loreto e Lilian Perdigão Caixêta Reis, no texto Crise dentro da crise, discorreram sobre a ampliação das desigualdades de inserção laboral juvenil durante a pandemia por coronavirus. Conforme os autores, as crises sanitárias e econômicas, em conjunto com a conjuntura de incertezas políticas, contribuíram para o aprofundamento dos problemas enfrentados pelos jovens no mercado de trabalho, em termos de precarização ou perda do trabalho, redução dos rendimentos, problemas relacionais e psicológicos.

No artigo Velhice e Telenovela Valmir Moratelli discutiu a representação da velhice na narrativa áudio-ficcional (novelas) alicerçada na construção de uma imagem social negativa do velho, marcada pela incapacidade e pelo preconceito, tão presente na contemporaneidade, sobretudo em momentos de pandemia, no qual os velhos receberam determinada visibilidade em função de representarem o principal grupo de risco para a doença.

Por último, no tocante da temática Trabalho, Categorias Profissionais e a Pandemia por Covid-19, foram aprovados dois artigos. No ensaio teórico Assistência Social em tempos da Covid-19, Cristiane Natalício de Souza analisou a destinação de recursos do fundo público brasileiro à política de transferência de renda em tempos da Covid-19, sob a possibilidade de a política ser interpretada como um direito e não como benesse. A autora discute o remodelamento 
do processo de reestruturação produtiva, enfatizando a impossibilidade de superar a política de transferência de renda.

No artigo Pandemia da Covid-19 e os impactos no ensino em enfermagem, Luís Felipe Pissaia e Arlete Eli Kunz da Costa - em uma pesquisa de delineamento qualitativo, realizada junto a estudantes de enfermagem de uma Instituição de Ensino Superior do interior do Rio Grande do Sul, durante o segundo semestre de 2020 - identificaram a necessidade de utilização dos recursos digitais disponíveis para o ensino remoto, visando à proteção coletiva. Foram percebidas perdas na qualidade do ensino pelos alunos, suprimidas pela impossibilidade do ensino presencial.

Os artigos do Dossiê, no geral, apontam que as disparidades no âmbito do trabalho, as violências de gênero e os preconceitos etários enraizados na sociedade brasileira foram agravadas pelo contexto pandêmico, em função do encadeamento das crises sanitária, econômica e política. O processo de isolamento social decorrente da pandemia compromete a rede de cuidados externos, sobrecarregando as mulheres, que tradicionalmente são as cuidadoras, partindo do entendimento que as relações de cuidado estão na interseção entre dicotomias público-privado, informal-formal, trabalho remunerado e não remunerado. Por outro lado, o enfraquecimento da rede de cuidados externos também expõe as camadas mais vulneráveis da sociedade, fazendo aumentar os índices de violência doméstica. Concomitantemente, os artigos mostraram a adoção de ferramentas digitais para mediação de possíveis conflitos familiares, como foi apontado no artigo de Vanessa dos Santos Moura.

Em termos metodológicos, frente aos desafios impostos pela pandemia, observou-se a adoção de estratégias de pesquisa exclusivamente digitais, com a adoção de questionários online, bem como de artigos de revisão sistemática, com uso das plataformas digitais.

Além do dossiê, a seção Variatas agrupa seis artigos que refletem de maneira crítica o caráter interdisciplinar da revista, sobretudo os temas voltados para as discussões centrais: a Família e a Sociedade. As contribuições de diferentes pesquisadores e temáticas se intercambiam e contribuem para a compreensão dos múltiplos aspectos que envolvem as categorias família, consumo, envelhecimento e trabalho, apresentando discussões variadas e contemporâneas.

No artigo intitulado Relação entre trabalho e vida familiar, as autoras Suélem Silva Oliveira, Charlista Schinaider Saraiva, Tereza Angélica Bartolomeu e Rita de Cassia Bhering Ramos Pereira buscaram compreender o perfil das mulheres que atuam no serviço terceirizado de limpeza da Universidade Federal de Viçosa (UFV), bem como as inter-relações instituídas entre o trabalho exercido na instituição e suas vidas familiares. Verificaram que essas mulheres 
enfrentam o desafio de conciliar suas jornadas de trabalho na instituição e em sua vida familiar, exercendo uma dupla/tripla jornada de trabalho que impacta de forma significativa a vida dessas mulheres. A remuneração pelo trabalho na instituição é uma das únicas fontes de renda da família, sendo este emprego compreendido como de suma importância para todos os membros que compõe a organização familiar.

Correlacionado ao primeiro artigo, tem-se a contribuição de Marco Aurélio Muniz Corrêa de Carvalho, Amélia Carla Sobrinho Bifano, Márcia Barroso Fontes e Bruno Silva Olher, com o texto intitulado Bem-estar e perfil de trabalhadores terceirizados da Universidade Federal de Viçosa-UFV. Os autores desenvolveram reflexões sobre o perfil socioeconômico dos trabalhadores terceirizados, bem como as relações de bem-estar no trabalho dentro da UFV Observaram que há uma precarização na execução das atividades terceirizadas, tanto para homens quanto para mulheres, porém, há uma menor valorização do trabalho feminino, sendo as mulheres é postas em desvantagem na esfera do mundo do trabalho com menores salários e nível de escolaridade, por exemplo.

Dando continuidade a uma visão de caráter local, no artigo denominado Índices de preços ao consumidor em Viçosa - MG, Jader Fernandes Cirino buscou compreender 0 comportamento dos preços da certa básica no munícipio, que sofreu diversas alterações ao longo do tempo e não havia uma caracterização dessas mudanças, sendo a última realizada nos anos de 2005/2006. Assim, o autor propôs, ao longo do artigo, uma sistematização e apresentação desses reajustes a partir das análises da Pesquisa de Orçamentos Familiares (POF) dos anos de 2019/2020.

Seguindo as discussões, apresenta-se o estudo Os agricultores familiares e o significado social do dinheiro do Programa Nacional de Alimentação Escolar, de autoria de Renata Rauta Petarly e Antônio José Pedroso Neto. Os autores analisaram os significados que os agricultores familiares impõem ao benefício recebido pelo Programa Nacional de Alimentação Escolar (PNAE). Verificaram que o dinheiro do PNAE, no interior das famílias, possui significados diversos, mas é classificado como um dinheiro designado à instância do feminino, ou seja, das mulheres para utilização dentro do lar, na esfera doméstica, e, em alguns casos, este valor recebe valoração pejorativa, pois as famílias o têm como dinheiro para as coisas da casa, estando dissolvido no mundo doméstico, mais feminino que masculino.

No artigo Representação da Velhice, Nádia Marota Minó e Rita Márcia Andrade Vaz de Mello analisaram as representações sociais sobre a velhice, discutindo como os idosos são vistos em nossa sociedade, destacando os preconceitos, as dificuldades e os problemas as vantagens e as recompensas que envolvem o ser idoso. Como as visões estereotipadas sobre a velhice 
constroem formas subjetivas de vivenciar essa etapa da vida, $n$, refletindo, sobretudo, acerca, as autoras buscam desconstruir os estigmas construídos historicamente e socialmente sobre esses sujeitos; possibilitando, reflexões positivas em suas qualidades de vida e em suas interações sociais.

Por fim, trazendo uma análise sobre a Estratégias para o envolvimento do paciente em um cuidado seguro, Cecília Siqueira e Aline de Pinho Dias refletem as estratégias utilizadas por instituições de saúde para o envolvimento do paciente com sua família no processo de cuidado seguro, oportunizando uma maior motivação para o tratamento e aumentando a percepção e participação durante todo o processo.

Com o conjunto dos textos das seções Dossiê e Variatas espera-se que os artigos aqui apresentados oportunizem aos leitores e leitoras uma ponderação crítica e possibilite um intercâmbio entre áreas diversas, que problematizam reflexões sobre condições de trabalho, consumo, família e processos de envelhecimento e cuidado no nível local ou global oportunizando contribuições relevantes para as discussões e pesquisas na área das Ciências Sociais Aplicadas.

Agradecemos aos autores pelas contribuições e pelos debates apresentados, sobretudo neste contexto de pandemia e de isolamento social que vivenciamos. 